\title{
First record of the ant subfamily Aenictinae (Hymenoptera, Formicidae) from Saudi Arabia, with the description of a new species
}

\author{
Mostafa R. Sharaf ${ }^{1, \dagger}$, Abdulrahman S. Aldawood ${ }^{1, \ddagger}$, Magdi S. El-Hawagry ${ }^{2, \$}$ \\ I Plant Protection Department, College of Food and Agriculture Sciences, King Saud University, Riyadh \\ 11451, P. O. Box 2460, Saudi Arabia 2 Basic Sciences Department, Community College, Al-Baha University, \\ Al-Baha, Saudi Arabia, P. O. Box 1598, Project: Survey and Classification of Agricultural and Medical Insects \\ in Al-Baha Province
}

† urn:lsid:zoobank.org:author:E2A42091-0680-4A5F-A28A-2AA4D2111BF3

†urn:lsid:zoobank.org:author:477070A0-365F-4374-A48D-1C62F6BC15D1

§ urn:lsid:zoobank.org:author:1DBA1729-FB21-44F5-A704-1767A580BA2A

Corresponding author: Mostafa R. Sharaf(antsharaf@yahoo.com)

Academic editor: Brian Fisher | Received 21 June 2012 | Accepted 4 October 2012 | Published 11 October 2012

urn:lsid:zoobank.org:pub:54C69DDB-21C9-4069-A07D-E1BEFC4AD111

Citation: Sharaf MR, Aldawood AS, El-Hawagry MS (2012) First record of the ant subfamily Aenictinae (Hymenoptera, Formicidae) from Saudi Arabia, with the description of a new species. ZooKeys 228:39-49. doi: 10.3897/zookeys.228.3559

\begin{abstract}
The ant subfamily Aenictinae is recorded for the first time from the Kingdom of Saudi Arabia and for the second time from the Arabian Peninsula. A new species Aenictus arabicus sp. n., is described from the worker caste. Aenictus arabicus belongs to the A. wroughtonii-group and appears to be most closely related to $A$. rhodiensis Menozzi, but can be easily distinguished from the latter by the following characters: overall smaller size; cephalic index (head width/head length) small; occipital corners in lateral view rounded; antennal scape when laid back surpassing approximately two-thirds of head length; funicular segments 2-8 each at least $2 \times$ as long as broad; subpetiolar process well developed; petiole and postpetiole distinctly imbricate; gaster and clypeus entirely yellow, teeth of mandibles reddish- brown. Aenictus arabicus was collected from leaf litter, next to a tree of Psidium guajava L. The new species also is similar to $A$. sagei and A. wroughtonii. Affinities and a key to related species of the species group are given.
\end{abstract}

\section{Keywords}

Aenictus, taxonomy, Arabian Peninsula, Saudi Arabia, Al Sarawat Mountains, ants, Palaearctic region

Copyright Mostafa R. Sharaf et al. This is an open access article distributed under the terms of the Creative Commons Attribution License 3.0 (CC-BY), which permits unrestricted use, distribution, and reproduction in any medium, provided the original author and source are credited. 


\section{Introduction}

The subfamily Aenictinae Emery, 1901, was elevated to the rank of subfamily by Bolton (1990), and includes a single genus, Aenictus Schuckard, 1840. The genus presently has 177 species and subspecific forms (Bolton 2012), distributed through the East Mediterranean, Afrotropical, Oriental, Indo-Australian, and Australian regions (Gotwald 1995, Brown 2000, Aktaç et al. 2004, and Jaitrong and Yamane 2012). Most of the species are tropical (Brown 2000), with terrestrial habitats, foraging in soil, leaf litter, most of the Southeast Asian species forage on the ground, and some on trees (e.g., Hirosawa et al. 2000) and hunting other ant species and termites (Gotwald 1995, Rosciszewski and Maschwitz 1994).

The subfamily Aenictinae is characterized by having:- a waist of two segments, with the spiracle of the postpetiole set behind the midlength of the tergite; all gastral spiracles circular; and the first gastral segment with a narrow, neck-like constriction behind the articulation with the postpetiole, 8-10 antennal segments, the frontal lobes reduced with the antennal sockets completely exposed, and the promesonotal suture absent (Bolton 1994). Species of Aenictus are generally small, monomorphic and yellow to dark brown. Members of the Aenictus wroughtonii-group share the following characters (Jaitrong et al. 2010): head narrow; posterior margin of head lacking collar; antennae long, 10-segmented; with long scape reaching or surpassing posterolateral corners of head; anterior clypeal margin bearing 5-10 denticles; mandibles subtriangular, with masticatory margin bearing 8-12 minute teeth in addition to a large apical tooth with a sharp apex; frontal carinae short; mesosoma narrow and elongate; legs thin and long; head entirely smooth and shiny; almost entire body clear yellow to yellowish brown.

Since Wilson's (1964) revision, several authors have published taxonomic papers dealing with particular areas or species groups, e.g., Zhou (2001) (South China), Shattuck (2008) (Australia), Terayama (2009) (Taiwan), Zettel and Sorger (2010) (Borneo and the Philippines), Jaitrong and Yamane (2012) (Southeast Asia), and Bharti et al. (2012) (India). A catalogue of the 35 known Afrotropical members can be accessed on the website of Taylor (2012), with photographs also on Fisher's Antweb.org (2012).

Ten species of Aenictus have been reported from the Palaearctic, nine of which are distributed in the Southwestern part of the region, Morocco in the west to Afghanistan in the east (Aktaç et al. 2004). Country records include A. rhodiensis from Greece (Menozzi 1936), Turkey (Aktaç et al. 2004), Iran (Radchenko and Alipanah, 2004) and Israel (Kugler 1988); A. fuscovarius fuscovarius Gerstäcker, A. fuscovarius sagittarius Santschi and $A$. hamifer Emery from Egypt (Sharaf 2006); and, an unidentified species from Yemen (Collingwood and van Harten 2001). The A. wroughtonii-group was revised for the Oriental and Indo-Australian regions (Jaitrong et al. 2010) giving seven species. The new species, $A$. arabicus belongs to this species group with resemblance to $A$. sagei and $A$. wroughtonii described by Forel from India. 
Here the subfamily Aenictinae is recorded for the first time from Saudi Arabia and for the second time from the Arabian Peninsula. A new species, $A$. arabicus sp. n., is described based on the worker caste. The queen and male are unknown. A key to the related species within the $A$. wroughtonii-group is given.

\section{Materials and methods}

The following abbreviations are used for particular morphological features and metrics:

TL Total length; the outstretched body length from the mandibular apex to the gastral apex.

HW Head width; the maximum width of the head in full-face view.

HL Head length; the maximum length of the head, excluding the mandibles.

CI Cephalic index $(\mathrm{HW} \times 100 / \mathrm{HL})$.

SL Scape length, excluding condylar bulb.

SI Scape index $(\mathrm{SL} \times 100 / \mathrm{HW})$.

ML Mesosoma length; the length of the mesosoma in lateral view, from the point at which the pronotum meets the cervical shield to the posterior base of the propodeal lobes or teeth.

PRW Pronotal width; the maximum pronotal width in dorsal view.

PL Petiole length; the maximum length of petiole measured in dorsal view, from the anterior margin to the posterior margin.

PW Petiole width; the maximum petiolar width measured in dorsal view.

PPL Postpetiole length; the maximum postpetiolar length measured in dorsal view.

PPW Postpetiole width; the maximum postpetiolar width measured in dorsal view.

All measurements are expressed in millimeters. Images were taken with a scanning electron microscope ((SEM) JSM-6380 LA).

\section{Depositories of type material}

BMNH Natural History Museum, London, United Kingdom.

CASC California Academy of Science Collection, San Francisco, California, USA.

KSMA King Saud Museum of Arthropods, King Saud University, Riyadh, Kingdom of Saudi Arabia (Holotype depository).

MCZC Museum of Comparative Zoology, Harvard University, Cambridge, MA, USA.

MHNG Muséum d'Histoire Naturelle, Geneva, Switzerland.

NHMB Naturhistorisches Museum, Basel, Switzerland.

SEMC Division of Entomology (Snow Entomological Collections), University of Kansas Natural History Museum, Lawrence, Kansas, USA.

WMLC World Museum Liverpool, Liverpool, United Kingdom. 


\section{Results}

Aenictus arabicus Sharaf \& Aldawood, sp. $\mathbf{n}$. urn:Isid:zoobank.org:act:347C091D-1E98-4765-AEF5-10C4CACE8DDE http://species-id.net/wiki/Aenictus_arabicus

Figs $1-12$

Holotype worker. Saudi Arabia, Al Baha-Mukhwah Aqaba RD,19.IV.2012, $20.00000^{\circ} \mathrm{N}, 41.43758^{\circ} \mathrm{E}, 1300 \mathrm{~m}, 19 . I V .2012$ (M. R. Sharaf leg.); deposited in the KSMA.

Paratype workers. 21 workers, same data as holotype; 1 deposited in MHNG (Dr Bernhard Merz); 1 deposited in NHMB (Mrs. Isabelle Zürcher-Pfander); 2 deposited in CASC (Dr Brian Fisher); 2 deposited in MCZC (Prof. E. O. Wilson); 2 deposited in SEMC (Prof. Michael S. Engel); 1 deposited in WMLC (Mr. Tony Hunter), 1 deposited in BMNH (Mr. Barry Bolton); the remaining specimens in KSMA (M. R. Sharaf).

Measurements. Holotype: TL 3.0, HL 0.65, HW 0.52, SL 0.50, PRW 0.35, ML 0.95, PL 0.22, PW 0.15, PPL 0.17, PPW 0.15. Indices: SI 96, CI 80.

Paratypes. TL $2.75-3.12$, HL $0.60-0.72$, HW $0.42-0.55$, SL $0.40-0.52$, PRW 0.20-0.35, ML 0.77-1.00, PL 0.22-0.27, PW 0.12-0.15, PPL 0.15-0.20, PPW 0.120.17. Indices: SI 77-104, CI 70-92. $(\mathrm{n}=11)$.

Description of worker. Head entirely smooth and shining. In full-face view head distinctly longer than broad, with convex sides and nearly straight posterior margin; occipital corners in lateral view rounded; anterior clypeal margin with six small denticles; masticatory margin of mandibles armed with a large apical tooth followed by five smaller subequal teeth and a relatively larger basal tooth; when laid back, antennal scapes surpassing about two thirds of head length; all funicular segments at least twice as long as broad; terminal funicular segment about $2.5 \times$ as long as the proceeding segment; mandibles dull with longitudinal striations; whole head dorsum and antennae with stiff scattered long hairs. Mesosoma in dorsal view broader anteriorly than posteriorly; promesonotum in profile distinctly convex, bearing many pairs of hairs; metanotal groove distinct; mesopleuron faintly but distinctly imbricate; propodeum bare or in some individuals with very sparse decumbent pubescence; propodeal dorsum long, about $4 \times$ as long as declivity; propodeum in profile slightly lower than promesonotum and almost flat dorsally; propodeal junction rounded. Petiole longer than broad in dorsal view with node clearly convex in lateral view; subpetiolar process triangular with convex ventral margin and blunt anteriorly. Postpetiole distinctly smaller than petiole, its node roundly convex, and its anteroventral edge sharp and bearing many hairs; both petiole and postpetiole distinctly imbricate and equipped dorsally with several pairs of backward directed long hairs. Gaster smooth and shining with abundant pairs of hairs. Color uniformly yellow.

Etymology. This species is named after the type locality. 

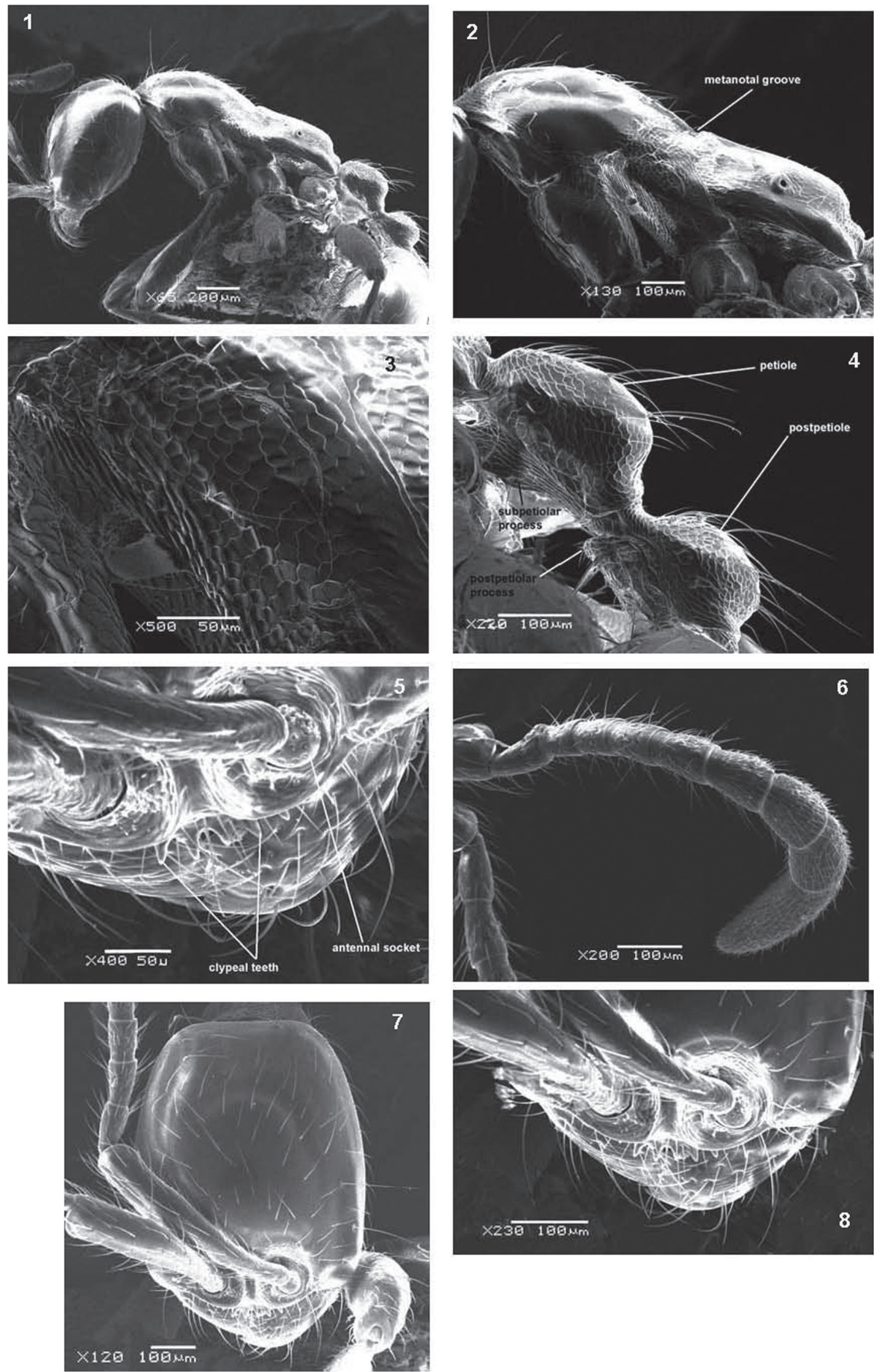

Figures I-8. SEM of Aenictus arabicus sp. n. paratype $\mathbf{I}$ body in profile $\mathbf{2}$ mesosoma in profile $\mathbf{3}$ imbricate sculpture of mesopleuron $\mathbf{4}$ petiole and postpetiole in profile $\mathbf{5}$ antennal sockets and anterior clypeal margin $\mathbf{6}$ antenna $\mathbf{7}$ head in full-face view $\mathbf{8}$ anterior part of head. 

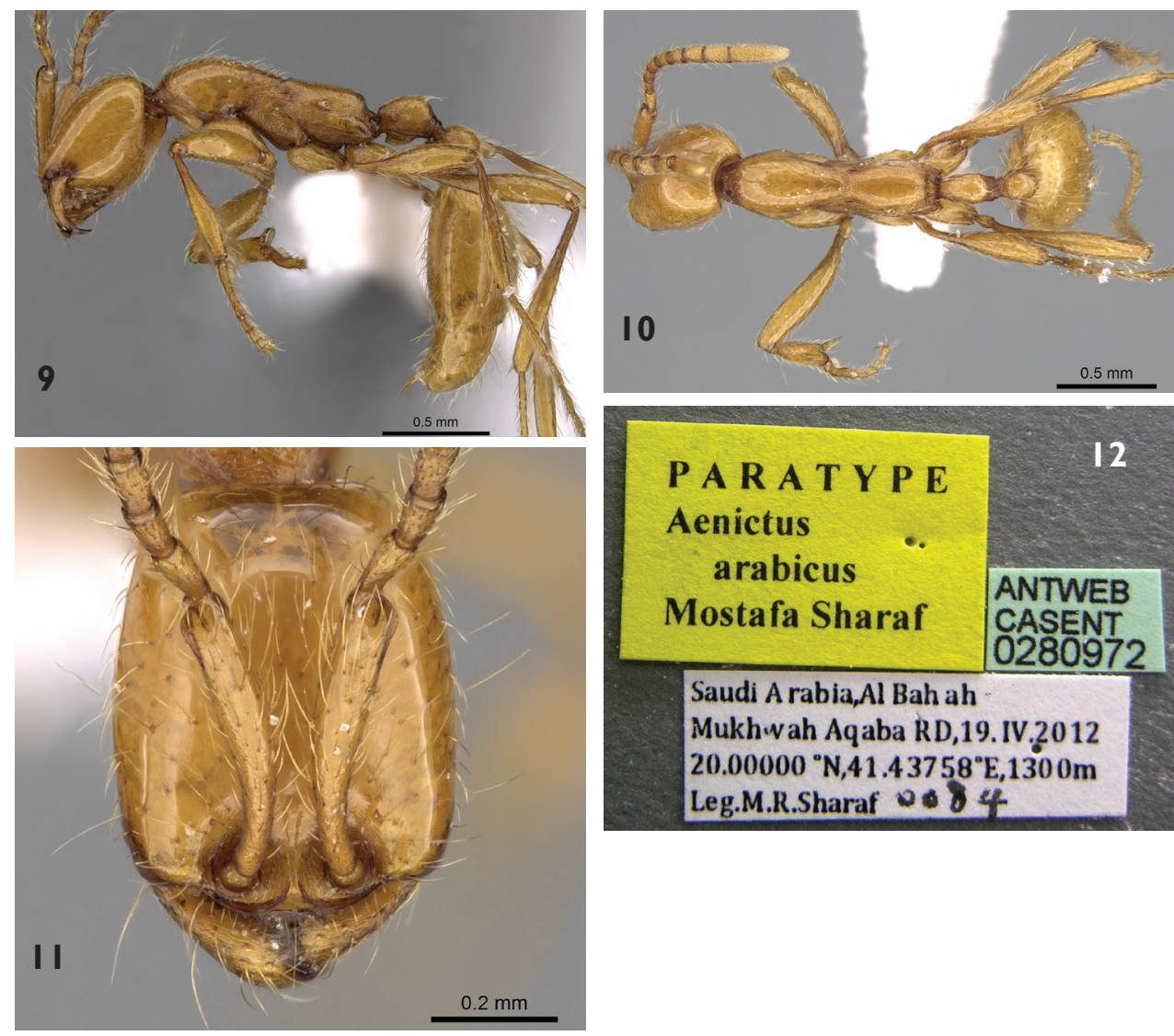

Figures 9-12. Automontage of Aenictus arabicus sp. n. paratype $\mathbf{9}$ body in profile $\mathbf{I} \mathbf{0}$ body in dorsal view I I head in full-face view I 2 label. ( CASENT0280972).

\section{Discussion}

Affinities. Aenictus arabicus is similar to $A$. rhodiensis Menozzi, 1936 from Greece; and $A$. sagei and $A$. wroughtonii described by Forel from India. All the three species are members of the $A$. wroughtonii-group as defined by Jaitrong et al. (2010) and sharing the following characters: head narrow, entirely smooth and shining; occipital margin lacking collar; antennae long, 10-segmented; anterior clypeal margin convex, rounded, with 5-10 denticles; mandibles subtriangular, with masticatory margin bearing 8-12 minute teeth in addition to a large apical tooth with a sharpe apex; mesosoma narrow and elongate; subpetiolar process weakly developed or almost absent; body clear yellow to yellowish brown.

Comparing $A$. arabicus with $A$. rhodiensis, both species have a similar general morphology, notably the shape of the mesosoma, petiole and postpetiole, a similar body pilosity; also both have a peculiar subpetiolar process which is somewhat wide and blunt anteriorly and the anterior clypeal margin is equipped with six small denticles. From the more accurate description in Aktaç et al. (2004), A. arabicus can be separated readily from $A$. rhodiensis. The former has a small relatively long, narrow head 
(HL 0.60-0.72, HW 0.42-0.55, CI 70-92) and long scapes, when laid back surpassing about two-thirds of the head length (SI 77-104) while the latter has a shorter head (HL 1.23, HW 1.02) and shorter scapes, which just surpass the midpoint of the head. Aenictus arabicus has a nearly straight posterior margin of the head whereas it is weakly concave in $A$. rhodiensis. The funicular segments 2-8 are at least twice as long as broad in the former, while they are as long as broad in the latter. Aenictus arabicus has an entirely yellow clypeus and reddish-brown mandibular teeth while the sides of the clypeus and mandibular teeth are reddish brown in $A$. rhodiensis. The gaster of $A$. arabicus is entirely yellow, whereas in $A$. rhodiensis, the middle of the third gastral tergite has two longitudinal brownish lines which diverge forward, sometimes reducing to small points. Aenictus dlusskyi Arnoldi, known only from the type series from Armenia, also resembles $A$. arabicus but is of a similar size to rhodiensis (Aktaç et al. 2004).

Comparing $A$. arabicus with the Asian species $A$. sagei (CASENT0281958) and $A$. wroughtonii (lectotype images are given in Jaitrong et al. 2010: 35), A. arabicus has the anterior clypeal margin bearing six small denticles; $A$. sagei has 9-10 denticles; whereas A. wroughtonii has 8-10 denticles. In addition, $A$. arabicus has the subpetiolar process well developed, triangular, with convex ventral margin and blunt anteriorly and body pilosity fewer and shorter; $A$. sage $i$ has a weakly developed subpetiolar process, with its ventral outline nearly straight; its anteroventral corners obtusely angulate and body pilosity distinctly long and abundant (length of the longest pronotal hair $0.20-0.25 \mathrm{~mm}$, Jaitrong et al. 2010); whereas $A$. wroughtonii has an undeveloped subpetiolar process, with its ventral outline feebly convex and without anterior angle and relatively sparse standing hairs which are shorter than in A. sagei.

\section{Habitat and biology}

Al-Baha Province is divided by massive and steep rocky mountains into the lowland coastal plain to the west, known as "Tihama", and the mountainous area ranging 1500 - $2450 \mathrm{~m}$ above sea level to the east, known as "Al-Sarat or Al-Sarah" which forms part of Al-Sarawat Mountains. The type locality (Fig. 13) is a small farm at the beginning of a narrow valley isolated between the mountains and the plain with a few native shrubs and trees at $1300 \mathrm{~m}$. The farm is planted with Annona squamosa L. (Annonaceae), Prunus persica (L.), P. Amigdalus (Mill.) (Rosaceae), Psidium guajava L. (Family: Myrtaceae), Zea mays ssp. mays L. (Family: Poaceae), in addition to banana, and mango. The new species was found foraging on the ground under leaf litter and next to a tree of Psidium guajava L. The soil, at the time of collection was well saturated through irrigation and accumulation of organic matter.

The climate in Al-Baha Province is greatly influenced by its varying topography. It is generally moderate in summer and cold in winter with average temperatures ranging between $12-23{ }^{\circ} \mathrm{C}$. In Tihama, the climate is hot in summer, warm in spring and mild in winter, with humidity ranging between 52\%-67\%, and a rainfall less than $100 \mathrm{~mm}$ annually. While in the mountainous area, Al-Sarah, The climate is greatly different from 


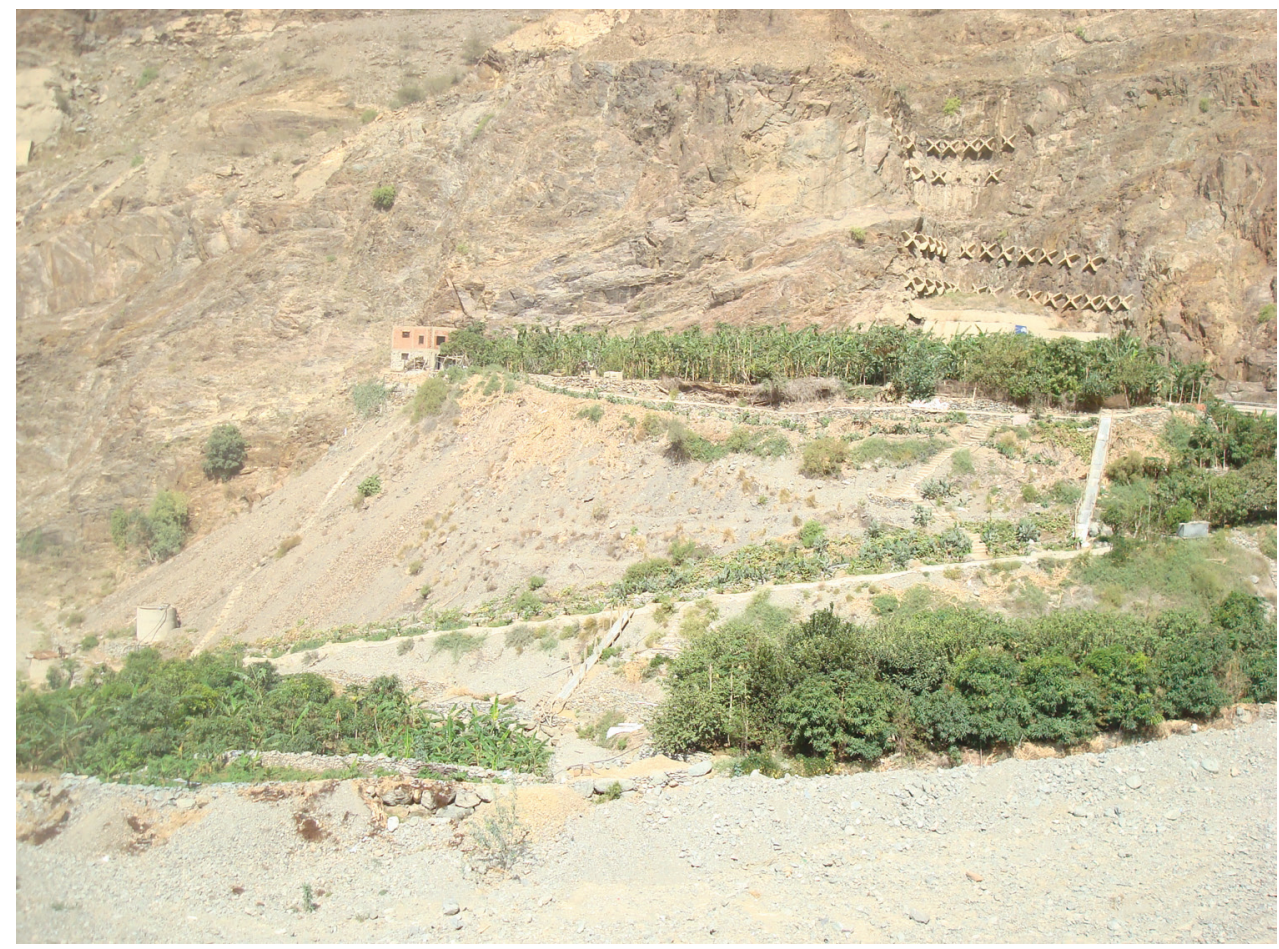

Figure 13. Type locality, Al Bahah, Mukhwah Aqaba RD. (photo M. R. Sharaf).

that in Tihama although they are separated by no more than $30 \mathrm{~km}$. The weather is cooler in summer and winter due to its high altitude. Al-Sarah is exposed to the formation of clouds and fog, and this often happens in winter because of air masses coming from the Red Sea, accompanied by thunderstorms. In spring and summer, the climate is mild and pleasant. Also, rainfall is higher with falls in the range of $229-581 \mathrm{~mm}$. The average rain falls throughout the whole province is $100-250 \mathrm{~mm}$ annually

Collingwood and van Harten (2001) recorded Aenictinae for the first time from the Arabian Peninsula based on an unidentified species, from workers collected in Yemen among leaf litter of banana plantations in Khamis Bani Sa'd and Lahj. The diagnostic characters given for this species indicate a similarity in general habitus to $A$. arabicus but in two characters mentioned by them, a broadly emarginate head and unique crenulation of the anterior clypeal border, their species disagrees with the present new species. Future collecting in Yemen is needed to clarify the status of this taxon.

The presence of an Aenictus species in the Southwestern part of Saudi Arabia is not surprising as the area is regarded as being Afrotropical (Bodenheimer 1937; Nayman 1972; Sharaf et al. 2012; El-Hawagry et al. unpubl. data), and it is likely that more Afrotropical ants are awaiting discovery in the area.

Despite the Afrotropical nature of the type locality we found it important to give a key to the closely related species in the $A$. wroughtonii-group. 


\section{Key to species of the Aenictus wroughtonii-group related to $A$. arabicus based on worker}

1 Subpetiolar process almost absent, anteroventrally not angulate (India) wroughtonii

- $\quad$ Subpetiolar process present, its anteroventral corners angulate .....................2

2 Anterior clypeal margin bearing 9-10 denticles; subpetiolar process weakly developed (India) ................................................................................. sagei

- $\quad$ Anterior clypeal margin bearing six denticles; subpetiolar process well devel-

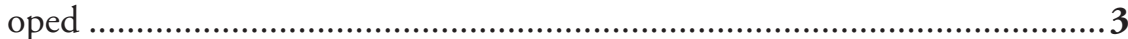

3 Funicular segments 2-8 as long as broad; middle of third gastral tergite with two longitudinal brownish lines, sometimes reducing to small points; scapes when laid back just surpass the midpoint of head (Greece) rhodiensis

- $\quad$ Funicular segments 2-8 at least twice as long as broad; gaster entirely yellow; scapes when laid back surpassing about two-thirds of head length (Saudi Arabia)

arabicus sp. $\mathrm{n}$.

\section{Acknowledgements}

This project was supported by King Saud University, Deanship of Scientific research, College of Food and Agriculture Sciences, Research Center. The authors are indebted to Barry Bolton, Brian Taylor, Boris Kondratieff and Michael S. Engel for their useful comments. We thank Brian Fisher and two anonymous reviewers for valuable suggestions. Special thanks to Lutfy El-Juhany (King Saud University) for identifying the plants from the type locality, Mahmoud Abdel-Dayem for technical assistance, Michele Esposito and Estella Ortega for taking automontage photos and Omer Hamid for SEM work.

\section{References}

Aktaç N, Radchenko AG, Kiran K (2004) On the taxonomy of the west Palaearctic Aenictinae (Hymenoptera: Formicidae). Annales Zoologici 54(2): 361-364.

Bharti H, Wachkoo AA, Kumar R (2012) Two remarkable new species of Aenictus (Hymenoptera: Formicidae) from India. Journal of Asia-Pacific Entomology 15: 291-294. doi: 10.1016/j.aspen.2012.02.002

Bodenheimer FS (1937) Problems of animal distribution in Arabia. Proceedings of the Linnean Society of London 148: 47-48.

Bolton B (1990) Army ants reassessed: the phylogeny and classification of the Doryline section (Hymenoptera, Formicidae). Journal of Natural History 24: 1339-1364. doi: $10.1080 / 00222939000770811$ 
Bolton B (1994) Identification guide to the ant genera of the world. Harvard University Press, Cambridge, Mass., 222 pp.

Bolton B (2012) Barry Bolton's Synopsis of the Formicidae and Catalogue of Ants of the World:1 January 2012. http://www.gap.entoclub.org/ [accessed 17 January 2012]

Brown WL Jr. (2000) Diversity of ants. In: Agosti et al. (Eds) Ants. standard methods for measuring and monitoring biodiversity. Biological diversity hand book series. Smithsonian Institution Press, Washington and London, 280 pp.

Collingwood CA, Harten AV (2001) Additions to the ant fauna of Yemen (Hymenoptera: Formicidae). Esperiana 8: 559-568.

Emery C (1901) Notes sur les sous-familles des Dorylines et Ponérines (Famille des Formicides). Annales de la Société Entomologique de Belgique 45: 32-54.

Fisher BL. Antweb. The California Academy of Sciences, San Francisco, U.S.A. http://www. antweb.org [accessed 17 January 2012]

Gotwald WH (1995) Army ants. The biology of social predation. Cornell University Press, New York, 320 pp.

Hirosawa H, Higashi S, Mohamed M (2000) Food habits of Aenictus army ants and their effects on ant community in a rain forest of Borneo. Insectes Sociaux 47, 42-49. doi: $10.1007 / \mathrm{s} 000400050007$

Jaitrong W, Yamane S, Wiwatwitaya D (2010) The army ant Aenictus wroughtonii (Hymenoptera: Formicidae: Aenictinae) and related species in the Oriental Region, with description of two new species. Japanese Journal of Systematic Entomology 16, 33-46.

Jaitrong W, Yamane S (2012) Review of the Southeast Asian species of the Aenictus javanus and Aenictus philippinensis species groups (Hymenoptera, Formicidae, Aenictinae). ZooKeys 192: 49-78. doi: 10.3897/zookeys.193.2768

Kugler J (1988) The zoogeography of social insects of Israel and Sinai. Pp. 251-275. In: Yom-Tov Y, Tchernov E (Eds) The zoogeography of Israel. Dr. W. Junk, Dordrecht. 600pp.

Menozzi C (1936) Nuovi contributi alla conoscenza della fauna delle Isole italiane dell'Egeo. VI. Hymenoptera - Formicidae. Boll. Lab. Zool. Gen. Agrar. R. Sc. Super. Agric. 29: 262-311. Nayman J (1972) Atlas of Wildlife. Heinenmann, London, 124 pp.

Radchenko AG, Alipanah H (2004) The first record of the subfamily Aenictinae (Hymenoptera: Formicidae) from Iran. Vestnik zoologii, 38(4): 75-78.

Rosciszewski K, Maschwitz U (1994) Prey specialization of army ants of the genus Aenictus in Malaysia. Andrias 13, 179-187.

Sharaf MR (2006) Taxonomic and ecological studies on family Formicidae (Order: Hymenoptera) in Egypt including some protectorates with a study of some insect fauna associated with ant species. Ain Shams University, Faculty of Science, Entomology Department, Cairo (unpubl. thesis), 340 pp.

Sharaf MR, Aldawood AS, Taylor B (2012) A new ant species of the genus Tetramorium Mayr, 1855 (Hymenoptera: Formicidae) from Saudi Arabia, Including a revised key to the Arabian species. PLoS one 7 (2) e30811: (1-9).

Shattuck SO (2008) Review of the ant genus Aenictus (Hymenoptera: Formicidae) in Australia with notes on $A$. ceylonicus (Mayr). Zootaxa 1926, 1-19. 
Taylor B (2012) The ants of (sub-Saharan) Africa. Aenictus catalogue. http://www.webarchive. org.uk/wayback/archive/20101217230548/http://antbase.org/ants/africa/aenictus/aenictus/aenictus.htm [accessed January 2012]

Terayama M (2009) A synopsis of the Family Formicidae of Taiwan (Insecta, Hymenoptera). Liberal Arts, Bulletin of Kanto Gakuen University 17, 81-266.

Wilson EO (1964) The true army ants of the Indo-Australian area (Hymenoptera: Formicidae: Dorylinae). Pacific Insects 6: 427-483.

Zettel H, Sorger DM (2010) Three new species of the army ant genus Aenictus Shuckard,1840

(Hymenoptera: Formicidae: Aenictinae) from Borneo and the Philippines. Zeitschr. der Arbeitsgemeinschaft österr. Entomologen 62, 115-125.

Zhou S (2001) Ants of Guangxi. Guangxi Normal University, Guilin. 